\title{
Biological and Nutritional Aspects of Human Milk in Feeding of Preterm Infants
}

\author{
Marzia Giribaldi $^{1^{*}}$, Laura Cavallarin ${ }^{1}$, Cristina Baro ${ }^{1}$, Paola Di Nicola ${ }^{2}$, Alessandra Coscia ${ }^{2}$, \\ Enrico Bertino ${ }^{2}$
}

${ }^{1} \mathrm{CNR}$ - Institute of Sciences of Food Production, Grugliasco, Italy; ${ }^{2}$ Neonatal Unit, Department of Pediatric and Adolescence Science, University of Turin, Turin, Italy.

Email: *marzia.giribaldi@ispa.cnr.it

Received September $27^{\text {th }}$, 2012; revised October $25^{\text {th }}, 2012$; accepted November $5^{\text {th }}, 2012$

\begin{abstract}
Breastfeeding and human milk are the normative standards for feeding and nutrition of both term and pre-term infants. Fresh mother's own milk is recognized as the optimal choice for feeding all newborns, including preterm and very low birth weight infants. Evidence documents short and long-term metabolic, immunologic and neurodevelopmental advantages of breastfeeding when compared to formula. Moreover, benefits of breastfeeding on psychological and relational aspects have to be considered. Currently, human milk supplementation is usually performed to meet the specific nutritional requirements of preterm infants. When mother's milk is unavailable or in short supply, donor milk represents the best alternative, although some nutritional elements are inactivated by the necessary pasteurization process. Aim of this review is to briefly summarize the main biological and nutritional factors that contribute to the beneficial effects of human milk feeding for preterm infants.
\end{abstract}

Keywords: Human Milk; Preterm Infants; Fortification; Donor Milk

\section{Introduction}

Increasing evidence currently shows that short- and longterm benefits of human milk (HM) feeding for term infants extend also to preterm and very low birth weight infants (VLBWIs) [1-3]. Mother's own milk is thus to be considered as the first choice for all infants. In order to meet the unique nutritional requirements of preterm infants and to preserve the singular benefit of breastfeeding, $\mathrm{HM}$ is recommended to be fortified to allow adequate growth and bone mineralization [4-6]. When mother's own milk is not available or in poor quantity, donor human milk (DM) represents the second best alternative $[7,8]$.

Clinical benefits of donor HM for premature newborns were recently surveyed [9]. Feeding preterm infants HM is reported to reduce significantly the rates of infection, necrotizing enterocolitis (NEC), and mortality, while improving neurocognitive and cardiovascular outcomes at the long-term.

Aim of this review is to briefly summarize the main biological and nutritional factors that contribute to the beneficial effects of HM feeding for preterm infants.

\section{Biological Aspects}

Human milk can be considered a species-specific biolo"Corresponding author. gical "dynamic" system. Particular attention is given to bioactive and immunomodulatory factors, such as gastrointestinal hormones, proteins and peptides, oligosaccharides, nucleotides, growth factors, antioxidants and cellular components, that can ensure adequate host defense against infections, as well as actively modulate the immune response and modify the intestinal bacterial flora [10-12].

\subsection{Proteins and Peptides}

Among the biologically active components that contribute to human milk uniqueness, proteins and peptides are known to exert a number of nutritional, immunological, antimicrobial and developmental functions. The most abundant HM proteins include important enzymes, components of the immune system, and dietary proteins [1316].

The immunoprotective protein constituents of HM include lysozyme, lactoferrin and immunoglobulins (Ig), known to act synergistically against bacteria. These proteins are present at high concentrations in HM: lysozyme is known to degrade the outer cell walls of Gram-negative bacteria, lactoferrin has bacteriostatic activity against iron-requiring pathogens, and antigen-specific secretory IgAs transfer to the newborn mother's immunity against 
several general pathogens. Immunoglobulins in HM represent the inheritance of mother's immunological competence, and allow the immune system of newborns to be "boosted" by acquired immunity in the mother $[13,16]$. The presence of these proteins represent a great advantage for both term and preterm infants, as they guarantee a shield for the newborns in an aggressive environment. Preterm babies, in particular, having an immature immune system, may benefit to a greater extend of this shield. The loss or the reduction of these immunoprotective protein constituents in HM following pasteurization is a major cause of skepticism for its suitability in infant feeding [17].

Other minor HM proteins can also act as components of the immune system and/or may display antibacterial activity, such as k-casein and haptocorrin [13]. Very recently, a proteomic research on the low abundance proteins of term and preterm HM [18] identified 120 proteins, $20 \%$ of total identified proteins, as involved in immune response. Among these proteins, some were identified for the first time in HM, and their possible role for the infant is not yet fully characterized. Furthermore, it is very interesting to note that several proteins whose abundance is modified in HM from term to preterm mothers are associated with the immune response, such as lactoferrin and lysozyme, showing an increased concentration in preterm milk, and polymeric Ig receptor, lactadherin, prolactin-inducible protein, Ig heavy chain, mucin-4, vitronectin, and C3 complement, more abundant in term milk.

Bioactive peptides exerting different physiological activities can also be generated from HM proteins in the gastrointestinal tract. Such peptides are usually encrypted within native protein precursors, and proteolysis is required for their release. Their small size is an advantage, as their intact absorption is more likely than that of the larger protein precursors. Bioactive peptides from milk can be divided into categories based on their physiological effect: antihypertensive, antithrombotic, opioid, antimicrobial, cytomodulatory and immunomodulatory [14]. Among HM bioactive peptides, the proteolytic fragments of caseins, and especially of $\beta$-casein, have been shown in experimental systems to have antithrombotic, antihypertensive, and opioid activities. Also, fragments of $\alpha$ lactalbumin, lactoferrin and HM caseins have been demonstrated to have antimicrobial capacities [13,14]. Bioactive peptides that generate from HM proteins represent one of the most promising target for research in nutrition.

\subsection{Oligosaccharides and Lactose}

Oligosaccharides have been recently described as important bioactive components in human milk, although they were originally isolated mainly as metabolic substrates for desired bacteria (and originally referred to as "bifidus factors”) [19]. Most updated surveys report that Human Milk Oligosaccharides (HMOs) directly act preventing pathogen adhesion to infant mucosal surfaces, lowering the risk for infections, and modulate epithelial and immune cell responses [20]. Comparison of the HMO content with milk from other species indicates that breast milk is unique in terms of complexity and content of oligosaccharides [21,22]. Qualitatively and quantitatively, HMOs presence in milk is strictly related to the expression of the mother's Se and/or Le genes. Substantial differences in HMO contents were found, and 4 different milk groups have been described according to the presence or the absence of specific fucosyl-oligosaccharides [23]. A recent study by Gabrielli and colleagues [24] reported new data on the oligosaccharide profiles and concentrations in the 4 milk groups. The higher oligosaccharide content in milk from mothers of preterm infants compared with those of term infants enforce the use of breastfeeding for preterm infants, who suffer from a greater risk of contracting infections, due to the immaturity of their organs and systems. The different HMO concentrations in preterm and term milk might represent a programmed adaptation of milk composition to the specific needs of the infants. The same survey also described a lower lactose concentration in milk from mothers of preterm newborns [24]. Low lactose concentrations in milk might have positive effects in preterm nutrition, because it contributes to lower milk osmolality. Low levels also might represent lower substrate levels for the developmental lactase deficiency that is common among these newborns [25].

\subsection{Oxidative Stress Response}

Preterm infants, who have a reduced antioxidant capacity, are often exposed to oxidative stress caused by infection, oxygen, mechanical ventilation, intravenous nutrition, and blood transfusions. Many of the disorders of preterm infants are thought to be due to this imbalance between antioxidant capacity and oxidative stress [26,27]. HM antioxidant components include the enzymes superoxide dismutase for dismutation of superoxide anion, catalase for degradation of hydrogen peroxide $\left(\mathrm{H}_{2} \mathrm{O}_{2}\right)$, glutathione peroxidase for destruction of $\mathrm{H}_{2} \mathrm{O}_{2}$, organic peroxides, and other oxygen scavengers, including cysteine and vitamins C and E [27]. Commercially available formula milks used in feeding preterm infants are also usually added with antioxidants in high amounts, such as vitamins $\mathrm{E}$ and $\mathrm{A}$. The efficacy of these supplemented antioxidants in scavenging free radicals has been frequently questioned in the past. No univocal response has been found yet, as methods for determining oxidative stress may vary according to the research group, the considered parameters and the methods of analysis. 
In the past, preterm and term HM have been found to have equal resistance to oxidative stress [28,29], better antioxidant protection $[28,29]$ and less oxidative damage [30] than formulas. Other research groups, on the opposite, found no difference in total antioxidant capacity between formula and HM or higher lipid peroxidation products in HM [31,32]. No significant difference was also found in the past in urinary MDA concentrations between healthy breast milk and formula fed infants [33].

As a general point of interest, the main advantage of feeding term and preterm infants with HM may consist in the complexity of the antioxidant strategies triggered. HM contains both hydrophilic and lipophilic antioxidants, including several vitamins, and a complete range of antioxidant enzymes, while formulas are supplemented for only few antioxidants, such as vitamin E.

\section{Nutritional Aspects}

\subsection{HM and the Use of Fortification}

For its nutritional qualitative advantages, HM is nowadays universally recognized as the optimal feeding choice for every infant [12]. However, for use in preterm infant feeding, nutrient supplementation is often recommended. Indeed, after the first weeks, the protein content of human milk is too low to permit adequate growth. Moreover, its low sodium level may lead to hyponatraemia, and the amounts of calcium and phosphorus could be below the intake needed to achieve fetal rates of bone mineral accretion [34]. Kuschel [4] and McCormick [35], in two recent surveys, agree that fortification of HM with more than one nutritional component is associated with short-term improvements in weight gain, linear and head growth. Further research should be directed toward comparisons between different fortifiers, evaluating both short-term and long-term outcomes and adverse effects, to evaluate an "optimal" composition of fortifiers $[4,35]$. The optimal method for HM fortification still remains to be determined, and a great variety of protocols are currently used in neonatal intensive care units (NICUs). HM protein content after standard fortification is too low to meet the recommended intake for preterm infants in approximately half of the cases [36]. Low protein intake has been proven to be the primary limiting factor responsible for growth failure of preterm infants. Fortification is usually based on the standard assumptions about the composition of HM. However, the protein concentration of preterm HM is variable, and decreases with the duration of lactation. Recently, better results have been obtained with individual fortification of human milk, that compensates for the variability of expressed HM composition, especially for protein and fat content. The two individual fortification models currently in use are "adjustable fortification”, based on the infant's metabolic res- ponse, and "targeted fortification", based on the HM analysis and on its fortification in such a way that each infant always receives the amount of needed nutrients [5].

Beside the total nutrient intake, another limiting factor for the developmental outcome of the newborns is related to the quality of both the protein and lipid fractions. The composition of these nutrient groups may have an influence on the feeding tolerance and on the absorbance of the supplied nutrients.

\subsection{Lipid Fraction}

An important nutritional attribute of human milk consists in its unique lipid profile and, in particular, in its n-6 and n-3 long chain polyunsaturated fatty acid (LC-PUFA) contents. Arachidonic acid (AA) and docosahexanoic acid (DHA) are essential to normal infant growth in the first year [37], and to retina and brain development [38]. Premature infants may suffer from reduced availability of AA and DHA to a greater extent than term infants, as $80 \%$ of these PUFAs accumulate during the last 3 months of pregnancy [39], and therefore have higher LC-PU-FA requirements. The importance in acquiring an adequate amount of these essential PUFAs is highlighted also by their common addition in infant formulas. Although the benefits of LC-PUFAs or fish-oil supplementation to mothers during pregnancy are noteworthy, no evidence of a positive effect of LC-PUFA supplementation on neurodevelopmental outcome of preterm infants is available [40]. Medium-chain saturated fatty acids (C 10-C14) are also considered of primary importance for infant nutrition, and especially for preterm newborns, as they are more easily absorbed than long-chain fatty acids [41]. However, a high rate of carbohydrate and lipid supply for preterm infants, based on the incomplete assumption that this is necessary to promote growth, tends to produce increased fat for organs like liver and heart, and more adipose tissue, which has no known benefit and many problems. Overfeeding with a higher quantity of lipids and carbohydrates has the definite potential to produce adipose tissue, or obesity, which then leads to insulin resistance, glucose intolerance, and diabetes [42].

\subsection{Protein Fraction}

As for HM lipids, the composition of the protein fraction, jointly with protein concentration, may have an influence on the infant development. Human and bovine milk display a significant difference in the ratio of whey proteins to caseins (60:40 in HM and 20:80 in bovine milk) and in the proportions of specific proteins. Moreover, HM was previously reported to change this ratio according to lactation period (about 90:10 in early lactation, 60:40 in mature milk and 50:50 in late lactation) [43]. The differences in the protein profiles of HM and infant formula 
have an impact on amino acid profiles, since different proteins have different essential amino acid contents, different biological value, and different bioavailability. Moreover, the use of protein supplements derived from non-human sources, such as plant or cow's milk proteins, may contribute to adverse reactions, such as allergy development.

HM proteins may contribute to infant growth also from another point of view: proteins may act as enzymes and/or carriers, and may thus facilitate the absorbance of other essential nutrients [13]. Bile salt-stimulated lipase, for example, is a lipolytic enzyme whose activity is triggered by the presence of bile salts in the infant's gut, that may help the digestion of HM lipids. Its presence, specific for milk from higher mammals, is particularly important in preterm infants, who have an immature digestive system [44, unpublished]. Lactoferrin facilitates the uptake of iron by human intestinal cells in culture [45]. Haptocorrin, or vitamin B-12-binding protein, and folatebinding protein may allow a gradual release and absorption of vitamins in infant's gut [13].

\section{Donor Human Milk}

American Academy of Pediatrics in its last policy statement on breastfeeding recommends that pasteurized DM, appropriately fortified, should be used if mother's own milk is unavailable or its use is contraindicated [1]. In many countries, HM banking is well established and standardized, and donor HM has become a health care component for preterm infants $[2,46,47]$. Pasteurization of HM is necessary to inactivate most of viral and bacterial agents. However, pasteurization inactivates some of the nutritive and biologically active compounds of $\mathrm{HM}$ $[10-17,48]$, which are considered to be responsible for its clinical benefits.

The main benefit deriving from the use of DM (vs formula milk) in preterm infant feeding is the reduction of the NEC incidence as indicated in three recent meta-analyses [49-51]. A reduction in the incidence of sepsis and of bronchopulmonary dysplasia as well as an enhanced feeding tolerance have also been observed $[2,8]$. However, further studies are necessary to confirm these data. Moreover, additional randomized controlled trials are needed to compare feeding with formula versus nutrient fortified DM, and also comparisons of formula and DM as supplements to maternal milk are desirable, since their effects may be different [51]. Analysis of costs and evaluation of acceptability are also required, in particular to explore different cultural, religious and social attitudes to DM [8,52].

Specific Guidelines have been prepared as a tool to optimize the operation of existing Human Milk Banks by standardizing their organization, management and procedures, and to determine the essential requirements to es- tablish a new Bank [2]. DM banks are not only meant to collect, process and store donated milk, but they also represent an instrument for breastfeeding promotion and support. In Italy, data from the Italian Neonatal Network show that in NICUs, exclusive breastfeeding at discharge is achieved for nearly $30 \%$ of infants when banked milk is available during hospitalization, whereas only for $16 \%$ of infants when it is not [53].

The role of health care workers, including pediatricians, is to protect, promote, and support breastfeeding. Health care workers should be trained in breastfeeding issues and counseling, and they should encourage practices that do not undermine breastfeeding. It is a health care paradox that breastfeeding is not adequately promoted and supported for preterm newborn infants admitted to NICU [54].

\section{Conclusion}

The importance of nutrition in the early period of life is now accepted, and the term "programming" has been proposed to emphasize that early nutrition should be considered also in terms of potentially long-lasting or lifelong biological effects [34]. A recent multicenter Italian study reported that breastfeeding and human milk use among the NICU infants at discharge are limited [55]. So, all efforts should be done for promoting and supporting breastfeeding in preterm newborn infants, as an extension of national breastfeeding policies.

\section{REFERENCES}

[1] American Academy of Pediatrics, "Breastfeeding and Use of Human Milk,” Pediatrics, Vol. 129, No. 3, 2012, pp. e827-e841. doi: 10.1542/peds.2011-3552

[2] S. Arslanoglu, et al., "Guidelines for the Establishment and Operation of a Donor Human Milk Bank," Journal of Maternal-Fetal and Neonatal Medicine, Vol. 23, No. 2, 2010, pp. 1-20. doi:10.3109/14767058.2010.512414

[3] C. Agostoni, et al., "Enteral Nutrient Supply for Preterm Infants: Commentary from the European Society of Paediatric Gastroenterology, Hepatology and Nutrition Committee on Nutrition”, Journal of Pediatric Gastroenterology and Nutrition, Vol. 50, No. 1, 2010, pp. 85-91. doi:10.1097/MPG.0b013e3181adaee0

[4] C. A. Kuschel and J. E. Harding, "Multicomponent Fortified Human Milk for Promoting Growth in Preterm Infants," Cochrane Database of Systematic Reviews (Online), No. 1, 2004. doi:10.1002/14651858.CD000343.pub2

[5] S. Arslanoglu, G. E. Moro and E. E. Ziegler, "Optimization of Human Milk Fortification for Preterm Infants: New Concepts and Recommendations," Journal of Perinatal Medicine, Vol. 38, No. 3, 2010, pp. 233-238. doi:10.1515/jpm.2010.073

[6] C. Di Natale, E. Coclite, L. Di Ventura and S. Di Fabio, "Fortification of Maternal Milk for Preterm Infants," 
Journal of Maternal-Fetal and Neonatal Medicine, Vol. 24, No. 1, 2011, pp. 41-43. doi:10.3109/14767058.2011.607569

[7] E. Bertino, et al., "Benefits of Donor Human Milk for Preterm Infants: Current Evidence,” Early Human Development, Vol. 85, No. 10, 2009, pp. S9-S10. doi:10.1016/j.earlhumdev.2009.08.010

[8] W. McGuire, "Donor Human Milk for Preterm Infants," Pediatrics, Vol. 130, No.2, 2012, p. e462. doi:10.1542/peds.2012-1647C

[9] S. Arslanoglu, E. E. Ziegler and G. E. Moro, "Donor Human Milk in Preterm Infant Feeding: Evidence and Recommendations," Journal of Perinatal Medicine, Vol. 38, No. 4, 2010, pp. 347-351. doi:10.1515/jpm.2010.064

[10] M. F. Picciano, "Nutrient Composition of Human Milk," Pediatric Clinics of North America, Vol. 48, No. 1, 2001, pp. 53-67. doi:10.1016/S0031-3955(05)70285-6

[11] L. A. Hanson, M. Korotkova and E. Telemo, "Breastfeeding, Infant Formulas, and the Immune System,” Annals of Allergy, Asthma and Immunology, Vol. 90, No. 6, 2003, pp. 59-63. doi:10.1016/S1081-1206(10)61662-6

[12] S. Fanaro and V. Vigi, "Feeding the Term Infant: Human Milk and Formula,” In: G. Buonocore, R. Bracci and M. Weindling, Eds., Neonatology. A Practical Approach to Neonatal Diseases: A Practical Approach to Neonatal Management, Springer, Milan, 2012, pp. 290-297. doi:10.1007/978-88-470-1405-3_44

[13] B. Lönnerdal, "Nutritional and Physiologic Significance of Human Milk Proteins," American Journal of Clinical Nutrition, Vol. 77, No. 6, 2003, 1537S-1543S.

[14] S. Mills, R. P. Ross, C. Hill, G. F. Fitzgerald and C. Stanton, "Milk Intelligence: Mining Milk for Bioactive Substances Associated with Human Health,” International Dairy Journal, Vol. 21, No. 6, 2011, pp. 377-401. doi:10.1016/j.idairyj.2010.12.011

[15] F. Michetti, et al., "The S100B Protein in Biological Fluids: More than a Lifelong Biomarker of Brain Distress," Journal of Neurochemistry, Vol. 120, No. 5, 2012, pp. 644-659. doi:10.1111/j.1471-4159.2011.07612.x

[16] C. Ballabio, et al., "Immunoglobulin-A Profile in Breast Milk from Mothers Delivering Full Term and Preterm Infants," International Journal of Immunopathology and Pharmacology, Vol. 20, No. 1, 2007, pp. 119-128.

[17] G. E. Moro and S. Arslanoglu, "Heat Treatment of Human Milk," Journal of Pediatric Gastroenterology and Nutrition, Vol. 54, No. 2, 2012, pp. 165-166. doi:10.1097/MPG.0b013e318235d629

[18] C. E. Molinari, et al., "Proteome Mapping of Human Skim Milk Proteins in Term and Preterm Milk,” Journal of Proteome Research, Vol. 11, No. 3, 2012, pp. 16961714. doi:10.1021/pr2008797

[19] S. Fanaro, et al., "Galacto-Oligosaccharides Are Bifidogenic and Safe at Weaning: A Double-Blind Randomized Multicenter Study," Journal of Pediatric Gastroenterology and Nutrition, Vol. 48, No. 1, 2009, pp. 82-88. doi:10.1097/MPG.0b013e31817b6dd2

[20] L. Bode, "Human Milk Oligosaccharides: Every Baby Needs a Sugar Mama,” Glycobiology, Vol. 22, No. 9,
2012, pp. 1147-1162. doi:10.1093/glycob/cws074

[21] C. Kunz, S. Rudloff, W. Baier, N. Klein and S. Strobel, "Oligosaccharides in Human Milk: Structural, Functional, and Metabolic Aspects," Annual Reviews of Nutrition, Vol. 20, 2000, pp. 699-722. doi:10.1146/annurev.nutr.20.1.699

[22] G. Boehm and B. Stahl, "Oligosaccharides from Milk," Journal of Nutrition, Vol. 137, No. 3, 2007, pp. 847S849S.

[23] S. Thurl, J. Henker, M. Siegel, K. Tovar and G. Sawatzki, "Detection of Four Human Milk Groups with Respect to Lewis Blood Group Dependent Oligosaccharides,” Glycoconjugate Journal, Vol. 14, No. 7, 1997, pp. 795-799. doi:10.1023/A:1018529703106

[24] O. Gabrielli, et al., "Preterm Milk Oligosaccharides during the First Month of Lactation,” Pediatrics, Vol. 128, No. 6, 2011, pp. e1520-e1531. doi:10.1542/peds.2011-1206

[25] M. B. Heyman, "Lactose Intolerance in Infants, Children, and Adolescents”, Pediatrics, Vol. 118, No. 3, 2006, pp. 1279-1286. doi:10.1542/peds.2006-1721

[26] S. Perrone, G. Salvi, C. V. Bellieni and G. Buonocore, "Oxidative Stress and Nutrition in the Preterm Newborn," Journal of Pediatric Gastroenterology and Nutrition, Vol. 45, No. 4, 2007, pp. S178-S182. doi:10.1097/01.mpg.0000302968.83244.d2

[27] A. Tsopmo and J. K. Friel, "Human Milk has Anti-Oxidant Properties to Protect Premature Infants," Current Pediatric Reviews, Vol. 3, No. 1, 2007, pp. 45-51. doi:10.2174/157339607779941615

[28] J. K. Friel, S. M. Martin, M. Langdon, G. R. Herzberg and G. R. Buettner, "Milk from Mothers of Both Premature and Full-Term Infants Provides Better Antioxidant Protection than Does Infant Formula,” Pediatric Research, Vol. 51, No. 5, 2002, pp. 612-618. doi:10.1203/00006450-200205000-00012

[29] N. Hanna, K. Ahmed, M. Anwar, A. Petrova, M. Hiatt and T. Hegyi, "Effect of Storage on Breast Milk Antioxidant Activity," Archives of Disease in Childhood: Fetal and Neonatal Edition, Vol. 89, No. 6, 2004, pp. F518F520. doi:10.1136/adc.2004.049247

[30] M. C. Michalski, C. Calzada, A. Makino, S. Michaud and M. Guichardant, "Oxidation Products of Polyunsaturated Fatty Acids in Infant Formulas Compared to Human Milk -A Preliminary Study," Molecular Nutrition and Food Research, Vol. 52, No. 12, 2008, pp. 1478-1485.

[31] E. Granot, D. Golan, L. Rivkin and R. Konen, "Oxidative Stress in Healthy Breast Fed versus Formula Fed Infants," Nutrition Research, Vol. 19, No. 6, 1999, pp. 869-879. doi:10.1016/S0271-5317(99)00047-0

[32] D. Turoli, G. Testolin, R. Zanini and R. Bellù, "Determination of Oxidative Status in Breast and Formula Milk," Acta Paediatrica, International Journal of Paediatrics, Vol. 93, No. 12, 2004, pp. 1569-1574. doi:10.1111/j.1651-2227.2004.tb00845.x

[33] O. Korchazhkina, E. Jones, M. Czauderna and S. A. Spencer, "Effects of Exclusive Formula or Breast Milk Feeding on Oxidative Stress in Healthy Preterm Infants," 
Archives of Disease in Childhood, Vol. 91, No. 4, 2006, pp. 327-329. doi:10.1136/adc.2005.084798

[34] M. De Curtis and J. Rigo, "The Nutrition of Preterm Infants,” Early Human Development, Vol. 88, No. 1, 2012, pp. S5-S7. doi:10.1016/j.earlhumdev.2011.12.020

[35] F. M. McCormick, G. Henderson, T. Fahey and W. McGuire, "Multinutrient Fortification of Human Breast Milk for Preterm Infants Following Hospital Discharge,” Cochrane Database of Systematic Reviews, Vol. 7, 2010. doi:10.1002/14651858.CD004866.pub3

[36] L. Corvaglia, et al., "Standard Fortification of Preterm Human Milk Fails to Meet Recommended Protein Intake: Bedside Evaluation by Near-Infrared-Reflectance-Analysis," Early Human Development, Vol. 86, No. 4, 2010, pp. 237-240. doi:10.1016/j.earlhumdev.2010.04.001

[37] S. E. Carlson, S. H. Werkman, J. M. Peeples, R. J. Cooke and E. A. Tolley, "Arachidonic Acid Status Correlates with First Year Growth in Preterm Infants,” Proceedings of the National Academy of Sciences of the United States of America, Vol. 90, No. 3, 1993, pp. 1073-1077. doi:10.1073/pnas.90.3.1073

[38] M. Neuringer, G. J. Anderson and W. E. Connor, "The Essentiality of N-3 Fatty Acids for the Development and Function of the Retina and Brain," Annual Review of Nutrition, Vol. 8, 1988, pp. 517-541. doi:10.1146/annurev.nutr.8.1.517

[39] M. Fleith and M. T. Clandinin, "Dietary PUFA for Preterm and Term Infants: Review of Clinical Studies," Critical Reviews in Food Science and Nutrition, Vol. 45, No. 3, 2005, pp. 205-229. doi:10.1080/10408690590956378

[40] M. Hadders-Algra, "Prenatal and Early Postnatal Supplementation with Long-Chain Polyunsaturated Fatty Acids: Neurodevelopmental Considerations," American Journal of Clinical Nutrition, Vol. 94, No. 6, 2011, pp. 1874S1879S. doi:10.3945/ajcn.110.001065

[41] C. Moltó-Puigmartí, A. I. Castellote, X. Carbonell-Estrany and M. C. López-Sabater, "Differences in Fat Content and Fatty Acid Proportions among Colostrum, Transitional, and Mature Milk from Women Delivering Very Preterm, Preterm, and Term Infants," Clinical Nutrition, Vol. 30, No. 1, 2011, pp. 116-123. doi:10.1016/j.clnu.2010.07.013

[42] W. W. Hay Jr., "Strategies for Feeding the Preterm Infant,” Neonatology, Vol. 94, No. 4, 2008, pp. 245-254. doi:10.1159/000151643

[43] C. Kunz and B. Lönnerdal, "Re-Evaluation of the Whey Protein/Casein Ratio of Human Milk," Acta Paediatrica, Vol. 81, No. 2, 1992, pp. 107-112. doi:10.1111/j.1651-2227.1992.tb12184.x

[44] E. Bertino, et al., "Effect of Prolonged Refrigeration on the Lipid Profile, Lipase Activity and Oxidation Status of Human Milk,” Journal of Pediatric Gastroenterology and
Nutrition, in Press. doi:10.1097/MPG.0b013e31827af155

[45] B. Lönnerdal, R. Jiang and X. Du, "Bovine Lactoferrin Can Be Taken up by the Human Intestinal Lactoferrin Receptor and Exert Bioactivities,” Journal of Pediatric Gastroenterology and Nutrition, Vol. 53, No. 6, 2011, pp. 606-614. doi:10.1097/MPG.0b013e318230a419

[46] Human Milk Banking Association of North America (HMBANA), "Guidelines for the Establishment and Operation of a Donated Human Milk Bank," Sandwich, MA, HMBANA, 2009.

[47] B. T. Hartmann, W. W. Pang, A. D. Keil, P. E. Hartmann and K. Simmer, "Best Practice Guidelines for the Operation of a Donor Human Milk Bank in an Australian NICU," Early Human Development, Vol. 83, No. 10, 2007, pp. 667-673.

doi:10.1016/j.earlhumdev.2007.07.012

[48] C. Baro, et al., "Effect of Two Pasteurization Methods on the Protein Content of Human Milk," Frontiers in Bioscience, Vol. 3, 2011, pp. 818-829. doi:10.2741/289

[49] C. A. Boyd, M. A. Quigley and P. Brocklehurst, "Donor Breast Milk versus Infant Formula for Preterm Infants: Systematic Review and Meta-Analysis," Archives of Disease in Childhood: Fetal and Neonatal Edition, Vol. 92, No. 3, 2007, pp. F169-F175. doi:10.1136/adc.2005.089490

[50] M. A. Quigley, G. Henderson, M. Y. Anthony and W. McGuire, "Formula Milk versus Donor Breast Milk for Feeding Preterm or Low Birth Weight Infants," Cochrane Database of Systematic Reviews, No. 4, 2007. doi:10.1002/14651858.CD002971.pub2

[51] W. McGuire and M. Y. Anthony, "Donor Human Milk versus Formula for Preventing Necrotising Enterocolitis in Preterm Infants: Systematic Review," Archives of Disease in Childhood: Fetal and Neonatal Edition, Vol. 88, No. 1, 2003, pp. F11-F14. doi:10.1136/fn.88.1.F11

[52] N. Modi, “Donor breast milk banking,” British Medical Journal, Vol. 333, No. 7579, 2006, pp. 1133-1134. doi:10.1136/bmj.39034.651563.80

[53] E. Bertino, F. Giuliani, C. Peila, P. Di Nicola, C. Vassia and S. Arslanoglu, "Benefit of Donor Human Milk in Preterm Infant Feeding,” Eaaarly Human Development, Vol. 85, No. 10, 2012, pp. S9-S10. doi:10.1016/j.earlhumdev.2009.08.010

[54] M. J. Renfrew, et al., "Breastfeeding Promotion for Infants in Neonatal Units: A Systematic Review," Child: Care, Health and Development, Vol. 36, No. 2, 2010, pp. 165-178. doi:10.1111/j.1365-2214.2009.01018.x

[55] R. Davanzo, L. Monasta, L. Ronfani, P. Brovedani and S. Demarini, "Breastfeeding at NICU Discharge: A Multicenter Italian Study,” Journal of Human Lactation, 2012, in Press. doi:10.1177/0890334412451055 